\title{
Mensurando a Maturidade na Tomada de Decisão em Sistemas de e-Participação
}

\author{
Cristiano Maciel \\ Instituto de Computação \\ Universidade Federal do Mato \\ Grosso \\ Cuiabá, MT, Brasil \\ cmaciel@ufmt.br
}

\author{
Licinio Roque \\ Departamento de Engenharia \\ Informática \\ Universidade de Coimbra, \\ Coimbra, Portugal \\ lir@dei.uc.pt
}

\author{
Ana Cristina Bicharra Garcia \\ Departamento de Informática \\ Universidade Federal do Estado do \\ Rio de Janeiro \\ Rio de Janeiro, RJ, Brasil \\ cristina.bicharra@uniriotec.br
}

\section{RESUMO}

A fim de viabilizar a integração de processos consultivos e deliberativos, é proposto o Modelo Interativo Governo-Cidadão, organizado em fases, sendo o debate estruturado por meio da Linguagem de Interação Democrática, a DemIL, e os cidadãos sociabilizados em uma comunidade virtual. Com vistas a diagnosticar a efetividade da participação dos cidadãos em processos com fins e-democráticos, apresenta-se o método Maturidade na Tomada de Decisão - MTD. O Modelo e o método são testados em dois experimentos e os resultados sumarizados neste artigo.

\section{PALAVRAS-CHAVE}

Interação baseada na Web, comunidades virtuais, redes sociais, governo eletrônico, tomada de decisão, maturidade.

\section{Introdução}

A participação dos cidadãos nas questões governamentais pode tornar real a democracia, uma vez que gera um fluxo contínuo de informações entre o cidadão e o governo, ambos auxiliando na tomada de decisões. Todavia, para que de fato haja democracia, os cidadãos devem articular um discurso, elaborar propostas, confrontá-las e indicar suas escolhas, por meios de difusão pública.

A democracia eletrônica permite viabilizar e consolidar tais processos consultivos e deliberativos. A problemática que surge nesse processo deve-se ao fato de que, quando os cidadãos são convocados a participar de consultas públicas e de processos deliberativos, ocorre, individualmente, uma transformação das informações oriundas de diferentes meios de comunicação (televisão, jornais, Internet, entre outros). Tal processo persiste até o momento da votação. Assim sendo, não se consegue verificar se há maturidade quanto às questões discutidas e deliberadas, garantindo que o indivíduo exerça de fato seu papel de cidadão.

Permission to reproduce or distribute, in whole or in part, material extracted from this work, verbatim, adapted or remixed, as well as the creation or production from the content of such work, is granted without fee for non-commercial use, provided that the original work is properly credited.

IHC 2019 - TRILHA ARTIGOS INTERNACIONAIS, Outubro 21-25, 2019, Vitória, Brasil. In Anais Estendidos do XVIII Simpósio Brasileiro sobre Fatores Humanos em Sistemas Computacionais. Porto Alegre: SBC.

(C) 2019 by the author(s), in accordance with the terms of the Creative Commons Attribution-NonCommercial 4.0 International Public License (CC BY-NC 4.0).
A fim de viabilizar a integração de processos consultivos e deliberativos, é proposto o Modelo Interativo Governo-Cidadão, organizado em fases, sendo o debate estruturado por meio da Linguagem de Interação Democrática, a DemIL, e os cidadãos sociabilizados em uma comunidade virtual. Com vistas a diagnosticar a efetividade da participação dos cidadãos em processos com fins e-democráticos, apresenta-se o método Maturidade na Tomada de Decisão - MTD [1].

Os experimentos para checagem das hipóteses da pesquisa foram realizados por meio de questionários online e de uma aplicação Web, a Comunidade Democrática Cidadã - CDC, possibilitando mensurar e classificar o grau de maturidade de cada cidadão responsável pela tomada de decisão. Por fim, classifica-se a tomada de decisão dos cidadãos em imatura, pouco madura, madura ou socialmente madura.

\section{Método Maturidade na Tomada de Decisão}

A maturidade é tida como a habilidade demonstrada por meio de contribuições ao processo (capacidades técnicas) e o comportamento observado quando o indivíduo interage na execução das tarefas (comprometimento do indivíduo, responsabilidade para com as tarefas, liderança, colaboração, competências organizacionais, entre outras). Sendo assim, maturidade de um grupo pode ser determinada pela predominância de maturidades individuais. Nesse sentido, apresenta-se um método para mensurar tal maturidade.

As etapas necessárias para a implantação do Método Maturidade na Tomada de Decisão (MTD) foram construídas com base no Modelo Interativo Governo-Cidadão. Como etapas identificadas como necessárias para o desenvolvimento do método proposto, há: 1) existir propósito sociedade, um interesse público, bem como do governo, em deliberar sobre tópicos de interesse; 2) Instaurar processo deliberativo, por etapas, conforme proposto no Modelo de Interação Governo-Cidadão; 3) definir instrumentos estruturados em conformidade com o processo para coleta de dados junto aos cidadãos. Para este estudo propõe-se o uso de questionários online ou de uma aplicação Web projetada para tal; 4) coletar dados; e 5) mensurar a Maturidade da Tomada de Decisão (MTD), ao término do processo, individual e do grupo, obtido da seguinte forma: $Y=f(M T D)$.

Para mensurar o grau de Maturidade na Tomada de Decisão tem-se como argumento um conjunto de indicadores do método 
[1]. De forma geral, tais indicadores indicam a intensão do indivíduo em participar do processo, a efetividade da participação do indivíduo no debate, a participação no debate representada pelo voto e o indivíduo socializa-se durante o processo, medindo o uso do espaço de sociabilização e o uso da biblioteca de informações. O processo de contagem dos dados é uniforme, sendo que para cada tarefa executada no ambiente de experimentação atribui-se uma determinada pontuação. Alguns indicadores têm limites para pontuação. Cada indicador possui um peso associado. Os pesos e pontuações atribuídas por indicador/variável podem ser encontradas no artigo original. A pontuação das variáveis associadas aos indicadores, bem como dos pesos atribuídos, podem ser adaptadas conforme a complexidade do processo edeliberativo.

Os grupos de classes propostos para o grau de maturidade são: Grupo 1- Imatura: interesse em participação e/ou moderação, todavia sem interesse posterior no processo deliberativo. Indiretamente mostra o desinteresse do público pelos assuntos propostos para discussão. Grupo 2 - Pouco Madura: participação no processo, no qual há interesse pelo debate ou pelo voto, não necessariamente por ambos. Grupo 3 - Madura: participação no processo, no qual há interesse tanto pelo debate quanto pelo voto. Grupo 4 - Socialmente Madura: processo participativo, efetivo e deliberativo, quando o cidadão participa de outras atividades, com uma frequência mínima. De um modo geral, há reciprocidade entre os membros, com fluxo de informações, com respeito às regras de uso e confiança entre os membros.

O grau de maturidade pode ser útil tanto para os cidadãos quanto para o governo. Com o tempo, os cidadãos podem entender como o método funciona e, desta forma, podem melhorar seu índice de maturidade. Para tal, o grau de maturidade deve estar visível ao usuário, podendo ser, para tal, utilizado um sistema de reputação. Para o governo, o método possibilita, além da realização de um processo deliberativo via Web, avaliar quantitativamente a tomada de decisão de questões de interesse público e observar qualitativamente as opiniões e interesses dos cidadãos com relação a dados assuntos.

\section{Experimentos e Análise de Resultados}

O Modelo Interativo Governo-Cidadão e o método MTD foram implantados e testados com a aplicação dos dois experimentos, de modo a analisar os grupos de classes propostos no MTD e testar as hipóteses desta pesquisa. Os experimentos foram via aplicação de questionários e por meio de uma rede social desenvolvida para tal, a Comunidade Democrática Cidadã - CDC.

O teste de hipóteses ofereceu uma abordagem confirmatória para a análise de dados com base na estatística. Assim, e como detalhado no artigo original [1], pode-se concluir que as médias das medições do método MTD são diferentes para uso de questionários e por meio da comunidade virtual CDC. Com base nesses resultados e nas análises qualitativas e quantitativas realizadas, as medições do método MTD aparentam ser melhores para o uso com a comunidade virtual CDC. Sendo assim, é aceita a hipótese alternativa da pesquisa, de que o método $Y=f(M T D)$ permite mensurar o grau de maturidade com relação à tomada de decisão em processos e-democráticos de forma ágil e integrada, por meio de uma comunidade virtual.

Nesse sentido, cabe enfatizar que, como o processo de contagem da pontuação do MTD é automático por meio da CDC, a aferição do grau de maturidade torna-se ágil. Também há ganhos com a integração de recursos importantes no ambiente, como a disponibilização de informações em uma biblioteca, e a possibilidade das pessoas socializarem-se, permitindo que os indivíduos sintam-se responsáveis pelas ideias compartilhadas e adquiram confiança com base no relacionamento mútuo estabelecido no ambiente. Deve-se considerar ainda a facilidade de inserção de novos recursos no ambiente integrado e, consequentemente, no método MTD, possibilitando adaptabilidade a ambos.

\section{Considerações finais}

A integração de ambientes consultivos e deliberativos para participação popular em questões democráticas e a formação de comunidades virtuais possibilitam a modelagem de processos de tomada de decisão. Dessa forma, fez-se possível a formulação do Modelo Interativo Governo-Cidadão e do método para mensurar a Maturidade na Tomada de Decisão nesse processo, conforme esforços desta pesquisa.

Em especial, apresenta-se como contribuições: a geração de um modelo participativo original, o Modelo Interativo GovernoCidadão, que permite estruturar um processo consultivo e deliberativo na Web, apoiado pela formação de comunidades virtuais, que possibilita o exercício da cidadania por parte dos cidadãos e transparência por parte dos órgãos governamentais; a oferta do método MTD, que possibilita mensurar a participação dos indivíduos em grupos deliberativos; e a oferta de uma abordagem diferenciada para modelagem e avaliação de comunidades virtuais, apresentando ainda uma métrica para mensurar a efetividade da participação dos indivíduos em um processo que integra discussão e voto, de forma ágil e integrada.

Com base nos trabalhos relacionados apresentados no artigo [1], pode-se constatar o diferencial das contribuições desta pesquisa no estabelecimento de um método para mensurar a maturidade de um processo deliberativo apoiado por uma comunidade virtual, classificando a participação dos usuários como imatura, pouco madura, madura ou socialmente madura. Limitações da pesquisa e trabalhos futuros são discutidos no artigo original [1].

Por fim, cabe ressaltar que se acredita que o método proposto pode ser aplicado em processos deliberativos distintos e em outros tipos de redes sociais e comunidades virtuais, desde que adaptados os indicadores de participação aos propósitos da aplicação.

\section{REFERÊNCIA}

[1] C. Maciel, L. Roque and A. C. B. Garcia. 2018. Maturity in decision-making: a method to measure e-participation systems in virtual communities. In: International Journal of Web Based Communities, $\mathrm{v}^{\circ} 14, \mathrm{n}^{\circ} 4$, pages 395-416. https://doi.org/10.1504/IJWBC.2018.096257. 